\title{
Colecionando museus como ruínas: percursos e experiências de memória no contexto de ações patrimoniais
}

\author{
Regina Abreu ${ }^{1}$ \\ UNIRIO, Rio de Janeiro, Brasil \\ E-mail: abreuregin@gmail.com
}




\section{Resumo}

O ensaio focaliza o tema do patrimônio e dos museus no contexto do Ocidente moderno, chamando a atenção para o fato de que a centralidade da noção de patrimônio que se afirmou durante os séculos XIX e XX caminhou lado a lado com o paradigma oculocêntrico da sociedade moderna: o sentido da visualidade terá a primazia sobre os demais. A ação patrimonial teve como marca fundamental a noção de que o objeto da preservação e da restauração não seria nunca um objeto total, mas uma seleção limitada e intencional. Ao selecionar um aspecto de memórias múltiplas e polissêmicas e ao concentrar os esforços para iluminar esse único aspecto, o movimento de patrimonialização seria também um movimento de apagamento. Desse modo, o artigo chama a atenção para o fato de que, como ruínas, os bens tombados ocultam também diversas ocupações e usos sociais. Com base na metáfora do flâneur e na proposta de recuperação da noção de experiência com base num novo colecionismo, a autora propõe uma metodologia de pesquisa (a etnografia dos percursos) para estudar os museus do Estado do Rio de Janeiro como ruínas.

Palavras-chave: Patrimônio. Memórias. Ruínas. Etnografia dos percursos.

\section{Abstract}

The essay calls attention to the fact that the notion of patrimony which was assumed in the western world during the 19th and 20th centuries ran parallel to modern society's oculocentric paradigm: visual sense occupying a privileged place over the remaining ones. Patrimonial action had as foundation mark the very notion that the object of preservation and restoration would never be a total object, but a limited and intentional selection. By selecting and highlighting only one aspect of multiple and polysemous memories, the movement of patrimonilization would also become a movement towards erasing. The article stresses that, as ruins, the goods under governamental trust also conceal many social occupations and uses. Based on the flâneur metaphor and on the notion of experience inspired in a new form of collectionism, the essay suggests a new methodology of research (rout ethnography) to study museums of Rio de Janeiro state as ruins.

Keywords: Patrimony. Memories ruins. Rout ethnography. 


\section{Paisagem, ruínas e a experiência do flâneur no contexto moderno}

o contexto do Ocidente moderno, o tema da paisagem adquiriu
singular contorno no período imediatamente posterior à Revolução Francesa. Nesse período, como assinala André Chastel, ocorreu importante afirmação de uma concepção nova de patrimônio que foi determinante nos anos que se seguiram para definir certos temas relacionados à ocupação do espaço. A primeira grande novidade é que o patrimônio passou a estar relacionado a um coletivo entendido como nacional. A segunda grande novidade é que o patrimônio colocou em movimento duas forças, a de preservação e a de destruição. O final do século XVIII e o início do século XIX foram pródigos em relatos de degradações, de profanações e de destruições de estátuas, de igrejas e de palácios. Todo um movimento de intelectuais iluministas foi posto em marcha para forjar um sentimento cívico de que era preciso preservar obras de arte, prédios históricos, palácios, igrejas e vestígios de outras culturas e outras civilizações. E também de que todas as aquisições artísticas e culturais de diferentes grupos sociais a partir daquele momento passavam a pertencer a um coletivo maior, a nação. Comissões e grupos de trabalho foram criados como a Comissão das Artes, precursora das instituições de defesa do patrimônio histórico e artístico nacional. Chastel (1986, p. 413) menciona que é nesse período que:

[...] o sentido do patrimônio, isto é, dos bens fundamentais inalienáveis se estendeu pela primeira vez na França às obras de arte, tanto em função dos valores tradicionais nelas incorporados como em nome de um sentimento novo de bem comum, daquilo que constitui uma riqueza moral para a nação. 
É nesse contexto que aparece a noção de vandalismo como atentado criminoso ao patrimônio. Os movimentos populares tendiam a demolir edifícios, portas e monumentos onde se inscreviam os nomes e a glória dos reis, vistos como testemunhos da opressão. Logo se gerou uma inquietação diante das vontades de esquecimento e de destruição e, em nome da arte, procurou-se construir um movimento oposto que preservasse para o conjunto da nação objetos, edifícios, palácios e monumentos identificados como de "valor artístico". Em 1792, um comitê destinado à preservação das obras de arte estabeleceu alguns pressupostos para uma ação que colocasse um freio nos anseios de destruição das lembranças do despotismo quando esses anseios ferissem obras de arte que pudessem ser usufruídas por todos. Alguns dos administradores da época, como o abade Grégoire, deixaram documentadas as dificuldades encontradas para a contenção das ondas de destruição. Ele narra que teria sido necessário conter ações de fúria que chegavam a propor o incêndio de bibliotecas públicas. “De todos os lados, partiam ataques a livros, quadros, monumentos que traziam emblemas da religião, da feudalidade, da monarquia. Foi incalculável a perda de objetos religiosos, científicos, literários." O abade relata que quando propôs o fim dessas devastações, ele foi chamado de fanático e acusado, sob o pretexto de conservar as artes, de salvar os troféus da superstição. Entretanto, tão grandes teriam sido os excessos que todos acabaram concordando com ele, promulgando no Comitê de Instrução Pública uma recomendação contra o vandalismo. Segundo o abade, o nome vandalismo teria sido criado por ele para cortar pela raiz o efeito cascata das destruições das obras de artes e dos patrimônios.

O sentido da noção de patrimônio, associado à ideia de bem público e à memória de um coletivo, incrementa-se durante o século XIX. Ao lado do movimento de preservação de bens considerados referências para uma sociedade, não podemos esquecer que as cidades cresciam trazendo os especuladores imobiliários. A destruição de prédios e de monumentos também era estimulada por interesses comerciais motivados pelo capitalismo industrial. Em 1832, o escritor Victor Hugo escreveu um artigo que se tornou célebre por dizer que, quaisquer que fossem os direitos da propriedade, não devíamos permitir que ignóbeis 
especuladores destruíssem edifícios históricos e monumentais. Para ele, haveria dois aspectos importantes nesses edifícios: sua utilidade e sua beleza. Mas, enquanto no aspecto utilitário o prédio pertencia ao proprietário, no aspecto da beleza o prédio pertencia a todos (tout le monde). Esse artigo emblemático sinalizou dois aspectos que seriam decisivos para a aquisição de um significado ocidental moderno da noção de patrimônio: de um lado, o conceito universal do belo, que desaguará na noção de um patrimônio universal ou da humanidade e, de outro, a crescente hegemonia da visualidade no campo patrimonial.

O patrimônio passaria cada vez mais a ser compreendido como um bem público para ser visto. Podemos, pois, afirmar que a centralidade da noção de patrimônio que se afirmou durante os séculos XIX e XX caminhou lado a lado com o paradigma oculocêntrico da sociedade moderna. O sentido da visualidade terá a primazia sobre os demais. É nesta chave que o tema da paisagem adquire especial significação. Preservar o patrimônio passou a significar também preservar uma paisagem, um cenário no espaço das metrópoles, um lugar para ser visto, contemplado e admirado. As novas configurações das cidades modernas passaram a incluir uma estética pautada na conjugação de elementos do passado com novas aquisições do capitalismo industrial. Prédios, monumentos, museus e obras de arte tornaram-se elementos de construção de paisagens nas cidades modernas. Essas referências do passado foram apropriadas por narrativas modernas no espaço urbano, convivendo lado a lado com diversos outros elementos que expressavam o progresso e a crença no futuro, a polissemia e a multiplicidade de informações das novas cidades.

O caso francês é emblemático. Em meados do século XIX, o arquiteto Viollet-le-Duc empreendeu um dos maiores esforços de restauração do espaço público na capital do país. Conjuntos arquitetônicos foram restaurados visando a constituir nova funcionalidade, estabelecendo importantes referências visuais nos principais espaços públicos da cidade. O importante a assinalar é que as restaurações de prédios, monumentos, museus e obras de arte não constituíram reproduções puras e simples do passado, o que ocorreu foi um movimento novo de apropriação de elementos do passado num contexto de crença e de 
exaltação do futuro. As importantes restaurações e os emblemáticos movimentos de preservação do patrimônio nos novos cenários urbanos também não foram uma reprodução pura e simples de todos os passados impregnados nos prédios em ruínas ou nos objetos salvos do vandalismo dos grupos sociais emergentes. Os movimentos patrimoniais que incluíam a identificação, a restauração, a preservação e a difusão de bens móveis e imóveis foram o produto de escolhas, de seleções, de decisões e de julgamentos. Os agentes do patrimônio não nasceram de movimentos sociais isolados ou contrários às novas tendências de administração do espaço urbano, pelo contrário, eles formaram desde sempre o que havia de mais moderno nas administrações nacionais, regionais ou locais. Seus ideais não eram nostálgicos, mas tinham o objetivo de universalizar as conquistas do mundo burguês. Assim, como administradores públicos, os agentes do patrimônio também tiveram que se perguntar: O que preservar? Quais prédios restaurar? Quais dos usos ou das características de um prédio ou de um palácio priorizar numa restauração? Quais estilos arquitetônicos manter e valorizar e quais os estilos arquitetônicos descartar ou apagar? Quais memórias iluminar e quais memórias apagar?

Desse modo, a ação patrimonial teve como marca fundamental a noção de que o objeto da preservação e da restauração não seria nunca um objeto total, mas uma seleção limitada e intencional. Ao selecionar um aspecto de memórias múltiplas e polissêmicas e ao concentrar os esforços para iluminar esse único aspecto, o movimento de patrimonialização seria também um movimento de apagamento. Desse modo, é preciso chamar a atenção para o fato de que, como ruínas, os bens tombados ocultam também diversas ocupações e usos sociais. Um palácio serviu a uma dinastia de reis, depois foi sede de governo, foi museu e depois ainda passou por um período de decadência para ser revitalizado e tornar-se uma biblioteca ou um centro cultural. Uma casa que serviu de residência a um industrial que a vendeu para um comerciante, depois foi transformada em uma casa de cômodos que foi adquirida pelo Governo para ser restaurada e abrigar uma biblioteca. Uma casa erigida em cima de um antigo sambaqui, depois serviu de residência a um barão de café que a vendeu a um industrial e depois 
abrigou uma fábrica de tecidos, que ficou em ruínas até que a prefeitura local a adquirisse para fazer uma escola. Todos esses exemplos apontam para a complexidade de sentidos e de significados que os patrimônios passaram mais a ocultar do que a evidenciar. O enorme esforço de restauração de prédios históricos que fez Viollet-le-Duc, em Paris, tranformando a cidade numa exuberante vitrine de vestígios do passado, pode ser apresentado como exemplo emblemático da conjugação destes dois movimentos: o da lembrança e o do esquecimento. Analisando as imagens dos prédios restaurados, como fez Bruno Foucart, ficam explicitados os apagamentos, os silenciamentos e os deslizamentos de sentidos (Foucart, 1986, p. 613-649).

Chegamos, pois, a um tema central formulado por Walter Benjamin na primeira metade do século XX que soou como uma profecia para os anos vindouros: a modernidade se converterá num mundo em ruínas. A instabilidade dos sentidos assombrará o mundo moderno. A velocidade das transformações imporá ao homem moderno um mundo presentificado, onde se tornará praticamente impossível preservar as referências com suas nuances e seus múltiplos e variados significados. O mundo moderno será sinônimo de novidade, apelando para a atualidade da informação. Nessa nova e original configuração, haverá uma desvalorização não do passado, mas da experiência, da tradição e dos elos que permitem aos sujeitos a articulação de múltiplas temporalidades. O patrimônio, segundo a vertente benjaminiana, expressará esse passado fetichizado, concebido como uma informação sobre aquilo que já se foi, opondo-se, portanto, ao passado atualizado como experiência, como vínculo entre sujeitos que se conectam por gerações. Todo esse movimento terá como cenário o espaço urbano, lugar de entrecruzamento de tradições e de culturas, de rapidez e de fluidez. O mundo rural com sua lentidão, com seu tempo de longa duração, se perderá inexoravelmente (Caiafa, 2007).

Entretanto, diferentemente do que poderíamos esperar, Benjamin não vê com maus olhos o espaço urbano. Pelo contrário, ele se deixa fascinar pelas possibilidades que a movimentação das grandes cidades traz com a diversidade humana, os variados estímulos e o ambiente de descontinuidades que interpelam os sujeitos e exigem 
deles novas posturas e modos de agir. Benjamin vai propor caminhos para a recuperação dos sentidos no espaço urbano. Ele centra seu olhar não numa direção do preservacionismo, das políticas de patrimônio, mas nas possibilidades que os indivíduos teriam para não se deixar engolir pelas transformações velozes e pela compressão do tempo (a presentificação). Com Benjamin, poderíamos pensar a modernidade como um espaço-tempo liso no qual caberia aos homens assumir o protagonismo de suas vidas, transformando esse espaço-tempo liso em rugoso, com reentrâncias, possibilidades e conjugações entre diferentes temporalidades.

É a partir de seu encontro com a poesia de Charles Baudelaire que o filósofo alemão sugere, no contexto da configuração moderna, algumas das mais criativas saídas para a retomada pelos sujeitos modernos da possibilidade da experiência. Sua principal aposta está na afirmação pelos sujeitos modernos de novas atitudes que os capacitem para um distanciamento e uma reflexão frente a uma enxurrada de estímulos à qual passaram a estar expostos. Benjamin elogia a atitude do flâneur, encarnada por Baudelaire, o observador apaixonado que caminha no espaço urbano e procura conviver com o movimento, o instante fugidio, a paisagem permanentemente transformada, e vai construindo novos sentidos, não se deixando oprimir pelas violentas transformações do mundo à sua volta. Apenas o flâneur, movendo-se pela cidade com um sentido poético, seria capaz de realizar uma escavação das camadas topográficas do espaço urbano. Sua tarefa consiste em encontrar as "correspondências" entre o antigo e o moderno, em articular a tradição no novo, na fantasmagoria de um mundo cercado por mercadorias.

O flâneur terá que lidar também com as implicações de certos dispositivos modernos, como a reprodução tecnológica da arte, nas mudanças da capacidade de percepção do mundo. Benjamin destaca uma espécie de "choque perceptivo" gerado por esses dispositivos desencadeando novas formas de olhar. As técnicas de colagem e de montagem - procedimentos típicos das vanguardas, cooptadas pelo cinema e pelo rádio, e naturalizadas na práxis vital da experiência moderna - se relacionam com a emergência dessa qualidade tátil, sinestésica 
e orgânica, que possibilita o que Benjamin nomeia como "recepção na dispersão". Ele chama ainda a atenção para as possibilidades de leituras que a modernidade engendra e que faz do leitor também um autor, um protagonista, um intérprete. Além disso, é a própria cidade, como espaço de exibição das mercadorias "poetizadas" (a fantasmagoria do novo) que transforma e reestrutura as faculdades perceptivas. O "choque" traz o sentido da fragmentação, da descontinuidade e da impressão brusca, mas também envolve a possibilidade de relação com o diferente, o exercício possível de construção da subjetividade na relação com a alteridade.

Benjamin, flâneur por excelência e colecionador incansável, sugere que manejemos a cidade como se o mundo fosse um texto. Como assinalou Sandra Valderatto, em Benjamin, o fragmento e a reticência adquirem uma importância teórico-metodológica por oposição a explicações esquemáticas, totalizadoras e fechadas. A partir do projeto de colecionar, Benjamin visa a captar um ritmo diferente nas coisas e a reconhecer novas configurações que não estão visíveis a priori. Essa forma de captação reticular, intersticial, constitui o princípio geral a partir do qual ele acredita ser possível reconstruir os nexos perdidos com o choque da modernidade (Valderatto, 1999).

Vamos então reter a alusão ao flâneur e a proposta de "perambular" ou "deambular" como estratégia para se inserir e se apropriar da dinâmica urbana fugidia, ilusória e transitória da cidade moderna. O flâneur não é um simples passante ou um contemplador nostálgico, ele se incorpora na multidão, percorre as galerias, enxerga as vitrines, se perde pelas ruas na busca pela memória, procura extrair o eterno do transitório. Podemos perceber a preocupação de Benjamin com a recuperação dos sentidos do passado na indagação: Como faz o indivíduo para traduzir sua necessidade interior de recordação no meio de uma realidade externa fragmentada? Assim o flâneur vai se apropriar do espaço urbano da cidade moderna a partir de sua experiência como colecionador de imagens, de cenas que não lhe pertencem e que passam pouco a pouco a constituir sua memória. Visto sob esse ângulo, o flâneur não descreve um acontecimento ou um lugar, ele o transforma. A cidade é para o flâneur, ao mesmo tempo, paisagem 
que se abre para o seu olhar e habitação que o acolhe. Ele passeia na cidade em busca dos lugares em que o passado ainda apresenta seus vestígios (Caiafa, 2007). ${ }^{2}$

A metáfora do flâneur pode ser compreendida como a possibilidade da revitalização da experiência no contexto urbano-industrial. Diante da tendência de fragmentação e de presentificação e da hegemonia do valor da informação como novidade absoluta, a retomada da experiência torna-se vital para os sujeitos, pois é nesse processo que eles se tornam protagonistas. O curioso argumento de Benjamin deságua na conclamação a percorrer um mundo em ruínas utilizando como ferramenta a proposta do colecionamento de imagens e de fragmentos de universos desaparecidos para que sejam tecidas novas configurações, sentidos e, consequentemente, novas ações transformadoras. É importante lembrar-se da adesão de Benjamin ao materialismo histórico e à ideologia comunista. Sob esse ângulo, a atitude do flâneur está longe de significar acomodação, mas pelo contrário expressa possibilidades de ações transformadoras.

\section{A metodologia do flâneur e os museus: etnografia dos percursos ou transformando ruínas em alegorias}

Passamos então para a segunda parte deste ensaio, no qual relatamos uma experiência de pesquisa em que buscamos inspiração na figura do flâneur para construir uma metodologia de pesquisa. É preciso antes fazer menção ao objeto da pesquisa propriamente dito em que esta metodologia foi aplicada como um exercício. Trata-se de uma pesquisa sobre os museus do Estado do Rio de Janeiro. A proposta consistiu em mapear qualitativamente os museus existentes no Estado, verificando a relação deles com as regiões onde se inserem. Em que medida os museus possuem também a função de contar histórias sobre a região em que se encontram? Até que ponto os museus expressam histórias locais ou regionais? Essas eram algumas das perguntas que serviram como ponto de partida para o projeto que foi desenvolvido com apoio da Fundação de Amparo à Pesquisa do Estado do Rio de Janeiro (Faperj) no âmbito de um edital voltado a contribuir para a sustentabilidade do Estado do Rio de Janeiro. ${ }^{3}$ Nessa parte do ensaio, deixaremos 
de lado os produtos que a pesquisa realizou e nos concentraremos no relato da experiência da pesquisa. Partindo das informações existentes no Cadastro Nacional de Museus que o Instituto Brasileiro de Museus (IBRAM) vem desenvolvendo, constatamos que no Estado do Rio de Janeiro há cerca de 300 museus, que estão distribuídos basicamente em duas grandes regiões: a cidade do Rio de Janeiro, que concentra mais da metade desse número; e o restante do Estado, que abarca a outra parte numa distribuição muito heterogênea. Há regiões ou cidades que concentram grande número de museus, como a cidade serrana de Petrópolis, e há outras regiões que não contam com praticamente nenhum museu, como a região noroeste do Estado. Decidimos de imediato que a pesquisa analisaria amostras de museus por região e que faríamos visitas e pesquisas de campo nesses museus. Desenvolvemos previamente um pequeno roteiro de visitações e fizemos contato com os museus explicando o teor do projeto e a necessidade de sermos recebidos por agentes que apresentassem o ponto de vista institucional.

A metodologia da "etnografia dos percursos" consiste em vivenciar a experiência do viajante que percorre uma região, buscando exercitar um olhar que estranha, inquire, indaga e que procura novos ângulos, perspectivas e novas faces de paisagens já vistas e consagradas. A etnografia, gênero de escritura que se desenvolveu com a tradição antropológica, guarda um parentesco com o diário de viagem ou o diário de campo. Uma característica central da etnografia é o fato de que o pesquisador se inclui na pesquisa e inclui também a relação com os outros, na medida em que procura expressar o pensamento dos segmentos pesquisados e dialogar com outras culturas e outras pessoas. É um trabalho artesanal. Na etnografia, importa o aspecto relacional, o aspecto experimental, o aspecto de construção dos dados da pesquisa a partir da visão do pesquisador no trabalho de campo.

Nosso objetivo consistiu em focalizar os museus como ruínas, pois assim seria possível encontrar muitas histórias sobre a ocupação das regiões onde eles se encontram. Para nós interessou desde sempre os diferentes fragmentos, sinais e vestígios por trás dos discursos prontos e codificados que os museus em suas monumentalidades expressam. Queríamos encontrar o Rio de Janeiro para além das paisagens con- 
sagradas, do outro lado do Pão de Açúcar, do Corcovado, das belas praias, da zona sul, para além da própria cidade do Rio de Janeiro. Ao focalizar o Estado do Rio de Janeiro queríamos levar ao extremo as consequências da duplicidade de sentidos, de um Rio de Janeiro Cidade e de um Rio de Janeiro Estado. Entendemos que essa superposição de nomes não é casual. Ela implica histórias complexas, expressando forças políticas contrárias, tensões e disputas. Habitar o Rio de Janeiro representa observar construções muito variadas e polissêmicas sinalizando cidadãos de uma cidade e/ou de um Estado. Identidades e diferenças que falam da proximidade com o mar, o litoral e com as conexões internacionais e que também falam do sertão, do interior, de conexões com outros estados: Minas Gerais, Espírito Santo ou São Paulo. Rio de Janeiro é sinônimo de foras e dentros, de cariocas e de fluminenses. Cartografar o Rio de Janeiro, palmilhá-lo, percorrê-lo significa lançar-se numa aventura de trilhas, de histórias e de imaginários raramente coincidentes. A polifonia da região está em cada trecho englobando áreas de ocupação muito antiga, em que praticamente toda a história do país é revista e recontada por muitas gerações de grupos sociais diferentes e contraditórios. Decididamente, não há registros únicos, e os museus vistos como ruínas podem nos trazer um pouco dessa polifonia de vozes. As pistas nos mostravam que a tendência seria caminhar por camadas de sentidos que convivem coetâneas, embora muitos séculos as separem. Numa mesma área, encontramos registros de quilombolas, de bandeirantes, de povos indígenas, de fazendeiros, de empresários, de aventureiros e de viajantes. Também de portugueses, franceses, tamoios, sambaquieiros, turcos, italianos, africanos e tupiniquins. Como cartografar uma região tão ampla e tão repleta de imaginários? Como trabalhar com a riqueza da diversidade de museus numa região que já foi sede do Governo português, da Colônia, do Império, da República? Uma região onde se fizeram as bases da economia do país, na qual surgiram as primeiras elites econômicas e políticas, as muitas relações de trabalho - escravidão, trabalho assalariado, serviços terceirizados? Como não perceber de imediato que muitos dos quase 300 museus do Rio de Janeiro contam também histórias do Rio de Janeiro, vestígios que são de antigas construções, fazendas, palácios, 
casas de remanescentes de quilombos e ruínas de antigas estações ferroviárias? Para a construção da nossa metodologia de pesquisa, esta foi, pois, nossa primeira assertiva: partimos da noção de que os museus do Rio de Janeiro eram signos de múltiplas narrativas sobre eles mesmos e sobre o espaço onde se inserem. Por outro lado, essas narrativas revelam um aspecto extremamente fragmentário, sinais de mundos já desaparecidos. Aliás, todas as tentativas de estabelecer grandes narrativas que os interligassem em algum sistema comum parecem ter fracassado. As classificações que outrora guiaram o universo dos museus e os subdividiram em categorias como históricos, artísticos, científicos, biográficos, etnográficos ou nacionais, locais e regionais parecem ter perdido o poder explicativo tamanha tem sido a diversidade de gêneros e a novidade no campo.

Assim encontramos lado a lado os grandes museus - como o Museu Histórico Nacional ou o Museu Nacional de Belas Artes - ancorados em representações do nacional. Há os museus centrados em personagens históricos como o Museu Casa de Rui Barbosa ou o Museu Casa de Benjamin Constant. Mas há também museus que se formaram pela nostalgia de mundos que desapareceram, como os museus ferroviários, espalhados por todo o estado e que tão bem expressam a saudade dos antigos ferroviários que viviam do trem e para o trem. Há vestígios muito antigos como os solares de Campos e Macaé, que testemunharam os primeiros aldeamentos indígenas, as missões jesuíticas, os ciclos econômicos da cana-de-açúcar, da transformação da cultura canavieira para a cultura cafeeira e, depois, para pastos de gado, e que agora observam atônitos a transformação da região pela força do petróleo e do pré-sal. São prédios imponentes que abrigaram originalmente corporações de jesuítas que ali fizeram as primeiras fábricas e as empresas lucrativas do país. Mas, há também museus que são coleções de toda uma vida, como o museu de conchas de Mangaratiba, resultado do esforço de um colecionador que conta a história das transformações do local por meio das conchas que foram desaparecendo e que ali jazem como testemunhas de épocas de biodiversidades mais pulsantes num local hoje repleto de habitações precárias, de lajes, de puxadinhos e de prédios de pequenos apartamentos, lançando-se em 
penhascos que se projetam para o mar. Ou ainda o Museu do Surf em Cabo Frio, resultado de uma coleção de um surfista fanático que é capaz de narrar por meio de seus preciosos objetos minúcias da história internacional do surf: a primeira prancha enorme de madeira, miniaturas de surfistas famosos, fotos antológicas, prêmios recebidos por destemidos desafiadores de ondas no Havaí... Ou ainda o Museu da Cachaça, resultado da coleção de um antigo aviador apaixonado por rótulos de garrafas de cachaça que disponibilizou "a coleção de uma vida inteira" para visitação pública na pequena cidade de Paty do Alferes, no centro-sul fluminense, iniciativa que vem contribuindo para a dinamização do turismo na região.

Eles estão por toda a parte, espalhados pelo Estado, sintoma de uma vitalidade enorme que abre um leque de inúmeras possibilidades de histórias e de memórias. De espaços consagrados aos grandes heróis da história pátria a espaços de valorização de pequenos heróis das mais ínfimas localidades, os museus constituem hoje espaços cada vez mais relevantes, respondendo ao nosso anseio por referências, elos e conexões com diferentes temporalidades. Como assinalou Andreas Huyssen (2000, p. 33):

[...] os museus nos seduzem e em certo sentido nos confortam. Aliviam o mal-estar que parece fluir de uma sobrecarga informacional e percepcional combinada com uma aceleração cultural, com as quais nem a nossa psique nem os nossos sentidos estão bem equipados para lidar. Quanto mais rápido somos empurrados para o futuro global que não nos inspira confiança, mais forte é o nosso desejo de ir mais devagar e mais nos voltarmos para a memória em busca de conforto.

Mas que conforto nós podemos esperar da memória e dos museus se hoje as grandes narrativas se perderam, se não há senão sentidos breves, fugazes, permanentemente construídos e negociados? Onde estão as memórias coletivas que se afirmavam em mitos e ritos? Onde estão os coletivos produtores de memórias persistentes? O que são os museus na contemporaneidade senão fragmentos cujos sentidos não escapam ao paradigma contemporâneo da fugacidade, da mudança, da velocidade? Mesmo essas instituições feitas para durar expressam 
cada vez mais dinâmicas de grande mobilidade. Muitos desses museus são permanentemente modificados, ressignificados e remanejados para atender a novas demandas de público, de ideias e de tendências.

A metodologia da "etnografia dos percursos" nos sinaliza para múltiplas possibilidades de leitura de rotas e de paisagens cujos museus configuram-se em sinais de tempos e de espaços variados. Se um prédio é conservado, se um acervo é preservado, se um museu é edificado e se isso faz parte de uma política cultural num município, podemos ler tal fato como significativo. Guardamos aquilo que faz sentido para nós e descartamos aquilo que não nos serve ou não queremos lembrar. A memória não se faz espontaneamente, ela necessita de agentes e de suportes, e os museus podem ser lidos como esses elementos que sinalizam algo sobre aqueles que os constroem e os mantêm. E também sobre os que os modificam ou os que os renegam e os destroem.

Assim, temos percorrido os museus que habitam o Rio de Janeiro como seres vivos, pulsantes e expressivos que contam histórias sobre espaços-tempos e que vêm despertando no pesquisador - flâneur do espaço urbano - certo sentido de alteridade absolutamente necessário para novos sentimentos e percepções das paisagens. É preciso experimentar o recurso flâneur na pesquisa, aceitando o convite de Walter Benjamin. Percorrer cada cidade e ir de uma cidade a outra, deixando-se levar pela satisfação de encontrar aberta uma porta de museu e simplesmente entrar. Solicitar a alguém que ali está que nos conte sua história e a história daquele museu. Abrir os sentidos para narradores experientes no sentido que Benjamin atribui para a categoria "experiência": alguém que tenha uma história pra contar porque inicia seu relato a partir da sua vivência, da sua relação íntima com o prédio, com os objetos e com a instituição.

Os sentimentos diante desses seres museais são diversos, também, porque são polifônicas as instituições, assim como as lembranças. Fazer a etnografia dos percursos em museus tem possibilitado que ecoem múltiplas vozes. Os museus são espaços com muitas camadas estratigráficas, que não raro são contraditórias. No caminho da cidade do Rio de Janeiro para a cidade de Araruama, na Costa do Sol, um museu apresenta, à primeira vista, a memória de uma fazenda de café com vestígios do que outrora foi uma casa-grande. Na parte de trás, 
há alguns fragmentos do que teria sido uma senzala. Mas, a grande surpresa é encontrar, neste mesmo espaço, ossadas e conchas encontradas numa escavação, deixando visível a memória dos sambaquieiros, povos antigos que viveram no Brasil antes dos tupis. A memória é assim. Não tem fim. Por debaixo de uma camada tem outra e outra e outra e mais outra. Memórias que nem sempre se encontram ou se combinam. Memórias que por vezes se contrastam, se enfrentam e se contradizem. O território das memórias não é um território apaziguado, pelo contrário, constitui um campo de disputas e de tensões. Não é tudo que fica. Fazer uma etnografia dos percursos no campo dos museus e do patrimônio pode ser uma contribuição da Antropologia para o encontro com uma pluralidade de sentidos e de significados que possibilite menos uma monumentalização do passado e mais uma humanização das memórias. É uma boa aposta.

Seguindo nosso percurso sobre os museus do Estado do Rio de Janeiro, encontramos também memórias que operam como contramemórias. Museus que longe de narrar histórias glamorosas, valorizam o esforço de populações pobres em construir suas trajetórias. Museus construídos em favelas ou em comunidades carentes. Museus com baixíssimo recurso e muita simplicidade, mas também muito eficazes no empreendimento de expressar histórias nunca antes relatadas.

Quais os significados desses espaços de memória? Quais as novidades que trazem? Há a impressão de que essas experiências estão trazendo formas de empoderamento social e de uma nova apropriação dos sentidos do espaço, transformando territórios lisos em paisagens rugosas, iluminando o que antes era opaco e invisível. São museus recém-criados em regiões de baixo Índice de Desenvolvimento Humano (IDH), regiões periféricas e estigmatizadas de espaços urbanos. Um desses museus que encontramos na pesquisa chama-se "Museu Vivo do São Bento". Foi criado num local degradado da região metropolitana do Rio de Janeiro: o Município de Duque de Caxias, conhecido no imaginário do carioca e do fluminense como local de grupos de extermínio e de milícias, aliado ao fato de abrigar o maior lixão da região - o aterro de Gramacho, hoje desativado - e ainda uma refinaria de petróleo, tudo contribuindo para a degradação da qualidade de vida dos moradores. Os moradores dessas paragens áridas da região 
metropolitana do Rio de Janeiro frequentemente internalizam um sentimento de baixa autoestima associando-se a um lugar periférico e relacionando-se de forma negativa com o espaço onde vivem. Suas aspirações incluem a busca por uma porta de saída deste lugar e o acesso a outros espaços valorizados socialmente. É nesse contexto que a iniciativa de alguns indivíduos, militantes da memória e do patrimônio locais, parece significativa. Ao procurar recuperar ainda que idealmente uma história local, em que um passado mais digno é acionado, esse grupo articula-se num esforço de reexistência, alterando a rota de um destino aparentemente letal. Os sujeitos dessa nova narrativa de esperança para o bairro de São Bento em Duque de Caxias são professores do ensino médio, a maior parte de História.

Essas iniciativas de patrimonialização e musealização inscrevemse em novas construções de percepções espaciais e de ressignificações de paisagens visando à dignidade social num espaço socialmente degradado. Outra experiência nesta direção é o Museu da Maré, construído no complexo de favelas da Maré, no Rio de Janeiro. Assim como o Museu Vivo do São Bento, essa obra partiu da experiência de jovens moradores do morro do Timbau que conseguiram chegar à Universidade e que fizeram desse acesso um caminho de volta para potencializar a própria comunidade onde nasceram e se criaram.

A etnografia dos percursos tem nos conduzido a mundos jamais imaginados, mundos que se situam na fronteira entre temporalidades muito distintas que, ao se mesclarem, ressignificam as experiências de vida e as percepções da paisagem. Nossos narradores ou guias de museus são intermediários em nossos objetivos de restaurar elos perdidos, vínculos que se romperam entre as muitas histórias que se superpuseram no contexto do Rio de Janeiro. Alguns, como os narradores do Museu Vivo do São Bento e do Museu da Maré são agentes do que Andreas Huyssen chama de rememoração produtiva, que podemos também denominar de rememoração propositiva, em que, escrevendo a história de um modo novo, os agentes sociais possam garantir um futuro de memória. O museu vivo do São Bento e o Museu da Maré associam-se claramente à expansão e ao fortalecimento de esferas públicas da sociedade civil, em que parece crucial essa ocupação da cidade pelos seus mais diversos cidadãos. É exatamente por meio de 
uma proposta de novas percepções de paisagens já tão sucateadas que se torna possível acalentar um fio de esperança no porvir. Esse fio de esperança ancora-se na alteridade produzida por imagens esquecidas de um passado pleno de dignidade. E isso se dá justamente porque esse passado, antes de se fundar na nostalgia, pelo contrário, anuncia a potência de novos agenciamentos.

\section{Notas}

1 Antropóloga, professora associada do Programa de Pós-Graduação em Memória Social e da Escola de Museologia da UNIRIO. É líder do Grupo de Pesquisa “Memória, Cultura e Patrimônio", cadastrado no CNPq. É autora de ensaios e livros sobre museus e patrimônios, entre os quais o livro Memória e Patrimônio: Ensaios Contemporâneos, RJ: Editora Lamparina, 2008.

2 Janice Caiafa (2007) lembra que “[...] mover-se numa cidade é uma experiência muito particular: envolve a geografia das ruas e a arquitetura da cidade, a relação com o trânsito de veículos e de pessoas, os estímulos de luzes, das lojas, as vozes humanas. É um modo de mover-se que produz, de fato, uma dança. Walter Benjamin (1995) escreveu sobre a situação de caminhar na cidade e de como o meio urbano trouxe para seus habitantes novos padrões perceptivos. Refere-se a essa experiência na cidade por vezes como uma experiência de 'choque' e fala de um movimento 'maníaco' que pode tomar conta do pedestre na cidade. Aí aparece a figura do transeunte, que Benjamin distingue em alguns momentos do flâneur. O transeunte tem seu movimento ditado pela agitação urbana e não frui de sua caminhada. O flâneur, ao contrário, é um habitante da cidade que deambula a seu bel-prazer. Tipicamente o flâneur anda a esmo, mas enquanto se opõe ao transeunte. Antes de tudo ele conta o tempo de seu andar, percorre as ruas em ritmo próprio. Essa distinção é interessante porque constitui um dos momentos em que Benjamin resgata um aspecto criador na experiência moderna - aqui com a figura do flâneur."

3 O edital da Faperj que viabilizou o projeto foi o Edital Pensa Rio 2007 e o projeto foi intitulado "Memória, Cultura, Transformação Social e Desenvolvimento: Panorama dos Museus do Estado do Rio de Janeiro" e foi realizado no Programa de Pós-Graduação em Memória Social da UNIRIO, com apoio da Escola de Museologia da UNIRIO e com a parceria do IBRAM. O projeto previu como resultados um portal (www.museusdorio.com.br), um livro e um programa de TV com os percursos visitados (também intitulado "Museus do Rio").

\section{Referências}

ABREU, Regina. Tal antropologia, qual museu? In: ABREU, R.; CHAGAS, M.; SANTOS, M. (Org.). Museus, coleções e patrimônios: narrativas polifônicas. Rio de Janeiro: MINC/IPHAN/DEMU/Garamond, 2007. 
. Museus etnográficos e práticas de colecionamento: antropofagia dos sentidos. In: CHAGAS, M. (Org.). Museus: antropofagia da memória e do patrimônio. Revista do Patrimônio Histórico e Artístico Nacional, Rio de Janeiro: Iphan, n. 31, p. 101-125, 2005.

CAIAFA, Janice. A aventura das cidades: ensaios e etnografías. Rio de Janeiro: FGV, 2007.

CHASTEL, André. La Notion de Patrimoine. In: NORA, Pierre (Org.). Les Lieux de Mémoire. La Nation, Paris: ed. Gallimard, 1986. p. 413.

CLIFFORD, James. Colecionando arte e cultura. Tradução de Anna O. B. Barreto. Revista do Patrimônio Histórico e Artístico Nacional, Brasília, n. 23, p. 69-89, 1994. Disponível em: < http://docvirt.com/docreader.net/DocReader. aspx?bib $=\backslash \backslash$ Acervo0 $1 \backslash$ drive_n $n \backslash$ Trbs $\backslash$ RevIPHAN $\backslash$ RevIPHAN.docpro $>$. Acesso em: 19 dez. 2012.

DIAS, Nélia. "Antropologia e museus: que tipo de diálogo?" In: ABREU, R.; CHAGAS. M.; SANTOS, M. (Org.). Museus, coleções e patrimônios: narrativas polifônicas. Rio de Janeiro: MINC/IPHAN/DEMU/Garamond, 2007.

FOUCART, Bruno. Viollet-le-Duc et la restauration. In: Les Lieux de Mémoire, v. II, La Nation, Paris, Éditions Gallimard, 1986. p. 613-649.

GRUPIONI, Luís Donisete Benzi. Coleções e expedições vigiadas. São Paulo: Hucitec, 1998.

HUYSSEN, Andreas. Seduzidos pela memória. Rio de Janeiro: Aeroplano, 2000.

VALDERATTO, Sandra. Lo urbano como la experiencia de la modernidad:

Baudelaire según Benjamin. 1999. Disponível em: < http://rephip.unr.edu. ar/bitstream/handle/2133/288/Valdettaro_Anuario_5.pdf?sequence $=1>$. Acesso em: 10 dez. 2012.

Recebido em 05/09/2012

Aceito em 10/10/2012 